|| ISSN(online): 2589-8698 || ISSN(print): 2589-868X || International Journal of Medical and Biomedical Studies

Available Online at www.ijmbs.info

PubMed (National Library of Medicine ID: 101738825)

Index Copernicus Value 2018: 75.71

Volume 3, Issue 4; April: 2019; Page No. 201-204

\title{
A CASE STUDY ON HYPOTHYROIDISM IN CHHATTISGARH
}

\author{
Naveen Gupta ${ }^{1}$, and K.L. Tiwari ${ }^{2}$ \\ ${ }^{1 \& 2}$ Pt.Deendyal Upadhyay Memorial Health Sciences and Ayush University, Raipur, Chhattisgarh
}

Article Info: Received 11 April 2019; Accepted 25 April. 2019

Cite this article as: Gupta, N., \& Tiwari, K. (2019). A CASE STUDY ON HYPOTHYROIDISM IN CHHATTISGARH. International Journal of Medical and Biomedical Studies, 3(4).

DOI: https://doi.org/10.32553/ijmbs.v3i4.219

Address for Correspondence: Dr. Naveen Gupta, Pt. Deendyal Upadhyay Memorial Health Sciences and Ayush University, Raipur, Chhattisgarh

Conflict of interest: No conflict of interest.

\section{Abstract}

Hypothyroidism in Chhattisgarh (India) is almost the second most common disease in middle aged and old aged females. First may be Diabetes / Hypertension / Arthritis / Osteoporosis. Hypothyroidism is caused due to under functioning Thyroid gland may be due to primary or secondary causes. The Etiology is still a mystery \& is unknown but having strong relation with genetics as well as the environmental pollution, food habits \& autoimmunity. The Thyroid gland regulates the metabolism of the body through the release of T3, T4 hormones \& have a negative feedback of TSH hormone. A case study was conducted on 70 patients from "Sai Kripa Clinic" Main Road Katora Talab Raipur, Chattisgarh, India.

Key words: Hypothyroidism, Autoimmune Disease, Obesity, Arthritis.

\section{Introduction:}

Hypothyroidism caused by underactive Thyroid \& also known as Myxoedema, which is a common disorder in females world wide. In our region hypothyroidism has became one of the basic diseases, like as Diabetes, Hypertension. We may consider that Thyroid as central gear in a sophisticated engine of human body. If this gear breaks or slows down the entire engine goes down. Hypothyroidism is mostly associated by musculoskeletal manifestations starting from Myalgias and Arthralgias to true Myopathy and Arthritis \& other sequelies. Patients with pain and stiffness over shoulder, knee \& small joints hands may be the isolated finding in many young woman \& man who were found severely hypothyroid in pathological evaluation.

Many literatures on bone and joint manifestations of hypothyroidism is seen with emphasis on cases where such manifestations were the presenting symptoms of
Hypothyroidism. Hypothyroidism is one of the most common thyroid disease in females, recently observed that up to $10 \%$ to $13 \%$ of women over 40 years of age. This suggests that a significant proportion of patient population may go undetected i.e subclinical and untreated even as it continues to impair the daily quality of life, work performance and economic productivity of an individual. On the other hand subjects who self-reported themselves to be hypothyroid, a significant proportion (28\%) still had a high TSH value is seen, some times incidentally detected while the routine blood tests of medical checkups.

Studies show that $90 \%$ of people with hypothyroidism are producing antibodies to their own Thyroid tissue. This causes the immune system to attack and destroy the Thyroid, which over time causes a decline in thyroid hormone levels resulting into Hypothyroidism. This autoimmune from of hypothyroidism is called Hashimoto's disease. Hashimoto's is the most 
common autoimmune disorder in the U.S. affecting between $7-8 \%$ of the population. While not all people with Hashimoto's have hypothyroid symptoms, Thyroid antibodies have been found to be a maker for future Thyroid disease in those individuals.

Most doctors know hypothyroidism is an autoimmune disease. but most patents don't because they are unable to detect a very slow progressing syndrome in their body. It is observed that autoimmune diseases travel in packs one for one or two free. If you have one you are at risk for developing other by default. For example people with Rheumatoid arthritis are also more likely to develop an underactive Thyroid disease \& may be cardiac involvement. Hypothyroidism or Hishimoto's Thyroiditis and may be vice-versa. Even in Rheumatoid the immune system mistakenly attack Thyroid cells interfering with their ability to make thyroid Hormones in normal quantity - these two conditions share genes may play role in susceptibility to auto immune diseases - certain HLA type mostly HLA-DR genes.

Every cell in our body has receptors for Thyroid hormone to act upon. These hormones are responsible for the most of all basic aspects of our body function, impacting all major systems of the body. Thyroid hormone directly acts on daily activities, growth, the brain, the G.I. tract Cardiovascular system, Bone metabolism, Red Blood Cell metabolism, Gall bladder and Liver function, Steroid hormone production, Glucose metabolism, Lipid and Cholesterol metabolism, Protein metabolism and body temperature regulation \& even on psychological behaviour of the patients.

It can be some times assumed as RA+ Hypothyroidism $=$ Heart disease?

Eric L Matteson M.D. Prof. Medicine at Mayo Clinic \& Rochoster Minn said "heart disease more prevalent among individual with bothHypothyroidism \& RA or more than one autoimmune conditions".
It's the Trifecta said Dr. Matteson "When you have an underactive thyroid, it can make you feel quite tired."

\section{There are many phrases common with Hypothyroidism as}

1. Hypothyroid is makes the patient obese.

In severe hypothyroidism the weight gain is due to water retention in the tissues

(hence the term "Myxoedema was given in old times.")

2. If the patient is having thyroid problem may complain -

Mark-able fatigue, anxiety, changes in pulse rate (Slowing down i.e. Bradicardia), hair loss, weigh gain loss \& dry skin with dark discoloration of skin taxure.

3. Thyroid disease affects both men and women and can present at any ages but more common in middle age $\&$ around perimenopausal age, although it is true that it is much more prevalent in women than men.

4. Sometimes it is precipitated in pregnancy \& may subside after delivery.

5. This may be a common cause for sterility in females.

6. This is found that if once the weight gain occurs due to Hypothyroidism it's very difficult to reduce it.

7. lodine is good for Thyroid health and 150 mcg daily is recommended for women in tpre-conception or during pregnancy and during breast-feeding to the kids.

8. There may be a lump in front of neck or may not be present.

9. Cold intolerance is noticed in this patient mostly in older age groups.

10. In my series the patients mostly presented with Polyarthrelgias not responding to usual NSAID course. Treatment. 


\section{Causes}

Hypothyroidism is observed globally but around 42-50 million people in India have Thyroid disorders. Hypothyroidism, specifically, is the most common of Thyroid disorders in India in comparison to Hyperthyroidism, affecting one in ten adults mostly in females. The prevalence of hypothyroidism in India is about $11 \%$, compared with only $2 \%$ in the UK and $4.6 \%$ in the USA. Compared with coastal cities (eg, Mumbai, Goa, and Chennai), cities located inland (eg, Kolkata, Delhi, Ahmedabad, Bangalore, and Hyderabad) have a higher prevalence ( $11 \cdot 7 \%$ vs $9 \cdot 5 \%$ ).

Now a days it is very much common in central part of India like the Madhya Pradesh \& in our state Chhattisgarh.

But in My clinical practice I am experiencing the increasing numbers of the cases in Chhattisgarh region in relation to the other states.

The Etiology is still yet to be discovered but there must a relation between Hereditary, uses of Chemical Fertilizers, Environmental Pollution \& strong connection with Autoimmune disease is definitely there.

There may be various causes of hypothyroidism which includes:

1. The most commonly seen cause of hypothyroidism is Hashimoto's Thyroiditis. Some others think it to be caused by different viral infections.

2. One important cause may be Radiation therapy: In many cases radiation therapy is given in neck for treating certain cancers, such as lymphoma, requires radiation to the neck.

3. Radioactive iodine treatment for hyper active Thyroid may later on land into Hypothyroidism.

4. Medicines like interferon alpha, Amiodarone (Cordarone), Lithium, and

Interleukin-2 may produce Hypothyroidism.

5. If Thyroid is removed surgically for Thyroid tumour may produce Hypothyroidism.

6. Pregnancy may precipitate Hypothyroidism.

Note -: Primary hypothyroidism is caused by a problem with the thyroid gland itself and
The Secondary hypothyroidism results from another problem which interferes with the Thyroid's ability to produce hormones.

Diagnosis

Blood tests are done for the diagnosis of hypothyroidism by estimating T3, T4 ,TSH.

\section{Complications of Hypothyroidism}

In My Observations with arthrelgias, arthritis \& musculoskeletal disorders in Chhattisgarh region as follows.

Note - This Disease may be associated with many associated diseases \& many joints may be involved in the same patient and the multiple symptoms may be common to many of the cases.

Table: 01 Associated Diseases

\begin{tabular}{|l|l|}
\hline Obesity & 43 \\
\hline Fatigue & 55 \\
\hline Polyarthrelgia & 36 \\
\hline Osteo Arthritis & 24 \\
\hline Rhumatoid Arthritis & 06 \\
\hline Ankylosing Spondilytis & 02 \\
\hline Ulcerative Colitis & 01 \\
\hline Diabetes Mallites & 10 \\
\hline Gout & 06 \\
\hline
\end{tabular}

Table- 02 Seasons of Aggravation

\begin{tabular}{|l|l|l|}
\hline Winter & Summer & Rainy \\
\hline++++ & ++ & +++ \\
\hline \multicolumn{3}{|l|}{ The number of patients increases very } \\
much with the change of whether, i.e. \\
any season changing into other. \\
\hline
\end{tabular}

Table 03: Joints Involved

\begin{tabular}{|l|l|}
\hline Knee & 18 \\
\hline Shoulder & 08 \\
\hline Lumber Spine(Low Back) & 15 \\
\hline Cervical Spine & 10 \\
\hline Tennis Elbow & 04 \\
\hline Sacroillitis & 05 \\
\hline
\end{tabular}




\section{Treatment:}

The evaluation of patients with new-onset hypothyroidism is increased in Chhattisgarh.

\section{Hypothyroidism is a rather TITRABLE than TREATABLE disease.}

The treatment is usually prolong, may need a life time medication. There is no permanent cure but it could be controlled by replacing the level of TSH, T4 and T3 hormones through medications. It is more important to check the age of a patient, causes, and TSH hormonal level.

Treatment of other associated diseases and care for musculoskeletal disorders are having equal importance. There are certain safety measures to be followed to control or to reduce the symptoms of hyperparathyroidism, which includes-

Having balanced diet including rich Vitamin D and calcium supplements to avoid the weakness and thinning bones.

Regular exercise, walking and exercises diet control \& weight loss work outs for managing weight gain.

Intake of more water and fresh fruit juice to avoid dehydration.

Smoking and consumption of alcoholsshould be avoided.

Regular hormonal level test to detect the functioning of thyroid gland every three months is advisable.

\section{Conclusion}

Hypothyroidism is a syndrome involving many systems of our body \& its prevalence is suddenly increasing in Chhattisgarh region. Clinicians have to focus upon the undetected \& silent or subclinical cases to prevent them from the complication of this almost endemic disease.

\section{References:}

1. New Delhi: Background Papers-Burden of Disease in India; 2005. National Commission on Macroeconomics and Health Ministry of Health and Family Welfare, Government of Ind2.

2. Desai PM. Disorders of the Thyroid Gland in India. Indian J Pediatr. 1997;64:11-20.ia.

3. Douglas S. Ross subclinical hypothyroidism. In: Braverman LE, Utiger RD, editors. Werner and Ingbar's The Thyroid: A fundamental and clinical text. 8th ed. Philadelphia: Lippincott Williams and Wilkins; 2000. pp. 1001-6.

4. Cooper DS. Clinical practice. Subclinical hypothyroidism. N Engl J Med. 2001; 345: 260-5.

5. Biondi B, Klein I. Hypothyroidism as a risk factor for cardiovascular disease. Endocrine. 2004;24:1-13.

6. Kalra $S$, Baruah MP, Unnikrishnan AG. Hypothyroidism in pregnancy: From unanswered questions to questionable answers. Indian J Endocrinol Metab 2013; 17:200-2

7. Hashimoto's disease. (2014, May). Retrieved from https://www.niddk.nih.gov/healthinformation/health-topics/endocrine/has himotos-disease/Pages/fact-sheet.aspx

8. Berber, E. \& Rehan, K. M. (2011, February 7). Preventing hypothyroidism. Retrieved from https://www.endocrineweb.com/condi tions/hypothyroidism/preventing-hypothyroidism

9. Hypothyroidism(underactive thyroid). (2016) https://www.niddk.nih.gov/healthinformati on /endocrine- diseases/hypothyroidism

10. Am J Med. 2010 Feb;123(2):183.e1-9. doi: 10.1016/j.amjmed.2009.06.030. 